\title{
Thrombotic thrombocytopenic purpura associated with pneumococcal sepsis
}

\author{
JeFFrEy R SCHRIBER, MD, JOHN J FREEDMAN, MD, JOSEPH M BRANDWEIN, MD
}

\begin{abstract}
JR SCHRIBER, JJ FREedMAN, JM BRANDWEIN. Thrombotic thrombocytopenic purpura associated with pneumococcal sepsis. Can $J$ Infect Dis 1993;4(3):145-147. The first documented case of thrombotic thrombocytopenic purpura (TTP) associated with pneumococcal septicemia is reported. This association has been previously demonstrated with hemolytic uremic syndrome. The patient presented with recurrent seizures, oliguric renal failure, fever, thrombocytopenia and microangiopathic hemolytic anemia; coagulation studies were normal. Blood and sputum cultures were positive for Streptococcus pneumoniae. The patient responded to therapy with plasmapheresis and antiplatelet agents as well as antibiotics. Coincident infection should be searched for in all cases of TTP.
\end{abstract}

Key Words: Plasmapheresis, Pneumococcal infections, Thrombotic thrombocytopenic purpura

\section{Purpura thrombocytopénique thrombotique associé à une septicémie pneumococcique}

RÉSUMÉ: Le premier cas documenté de purpura thrombocytopénique thrombotique associé à une septicémie pneumococcique a été rapporté. Cette association avait déjà été observée dans un syndrome urémique hémolytique. Le patient s'est présenté avec convulsions récurrentes, insuffisance rénale marquée par de l'oligurie, de la fièvre, de la thrombocytopénie, et anémie hémolytique microangiopathique. Les épreuves hémostatiques étaient normales. Les cultures de sang et d'expectorations étaient positives à l'égard de Streptococcus pneumoniae. Le patient a bien répondu au traitement par plasmaphérèse et agent antiplaquettaire de même qu'aux antibiotiques. Il faut toujours considérer la possibilité d'une infection concomitante dans tous les cas de purpura thrombocytopénique thrombotique.

$\mathrm{T}$ HROMBOTIC THROMBOCYTOPENIC PURPURA (TTP), INITIALLY described by Moschovitz (1), is characterized by the presence of consumptive thrombocytopenia, microangiopathic hemolytic anemia and neurological symptoms, frequently accompanied by renal failure and fever (2). The pathogenesis of this disease is unclear, although abnormalities of prostacycline and von Willebrand's factor have been described $(2,3)$.

Various infectious agents have been implicated in the etiology of this disorder as well as in the related hemolytic uremic syndrome $(4,5)$. Hemolytic uremic syndrome has been described in association with pneumococcal septicemia (6-10), including one adult (7); we report the first case of full-blown adult TTP in association with this infection.

\section{CASE PRESENTATION}

A 28-year-old woman with an uneventful past medical history and a one-week history of nausea, vomiting and diarrhea presented to the emergency room follow-

Division of Hematology, St Michael's Hospital, and University of Toronto, Toronto, Ontario

Correspondence: Dr J Brandwein, St Michael's Hospital, 30 Bond St, 2D-South, Toronto, Ontario M5B 1W8. Telephone (416) 864-5389, Fax (416) 864-5693

Received for publication March 13, 1992. Accepted September 1, 1992 


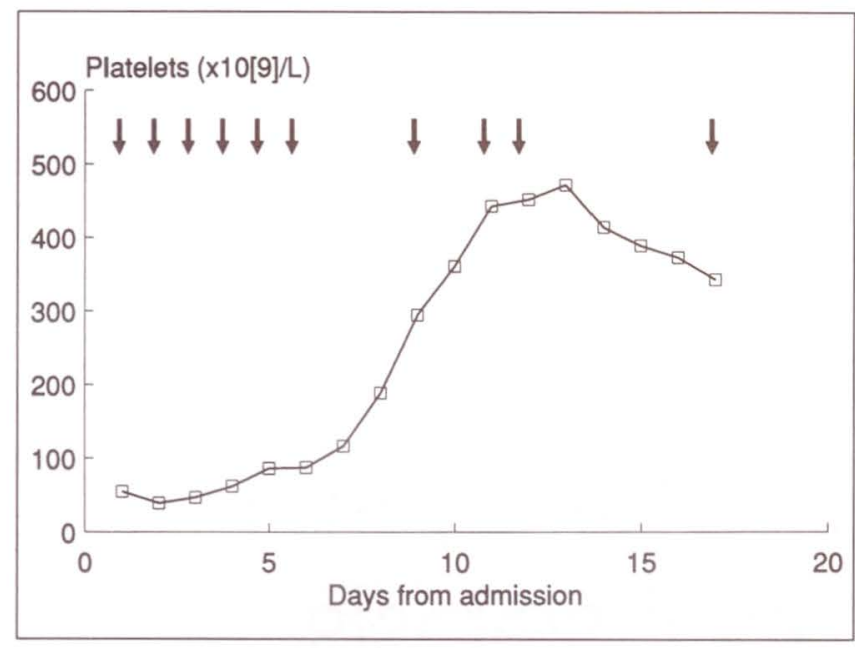

Figure 1) Platelet counts on successive days from presentation. Arrows indicate days on which plasmapheresis was performed

ing a generalized seizure. At presentation she was febrile $\left(37.9^{\circ} \mathrm{C}\right)$, responsive only to painful stimuli and displayed no focal neurological findings. Physical examination was otherwise unremarkable; notably, blood pressure was normal, there were no purpuric lesions and no findings of pneumonia.

Complete blood count on admission demonstrated a hemoglobin of $109 \mathrm{~g} / \mathrm{L}$, white blood cell count $19.8 \times 10^{9} / \mathrm{L}$ (neutrophils $77 \%$, bands $4 \%$, metamyelocytes $2 \%$, lymphocytes $8 \%$, monocytes $8 \%$ ) and a platelet count of $55 \times 10^{9} / \mathrm{L}$. Blood smear demonstrated marked red cell fragmentation and polychromasia. Blood urea nitrogen and creatinine were both elevated at $26.6 \mathrm{mmol} / \mathrm{L}$ and $425 \mu \mathrm{mol} / \mathrm{L}$, respectively. Serum lactate dehydrogenase was elevated at $1170 \mathrm{U} / \mathrm{L}$ (normal less than $150 \mathrm{U} / \mathrm{L}$ ), consistent with severe hemolysis. Beta human chorionic gonadotropin, performed to rule out associated pregnancy, was negative. Antinuclear antibody, rheumatoid factor and complement levels, performed to rule out vasculitis as a cause of microangiopathy, were normal. The initial chest $\mathrm{x}$-ray was normal. A lumbar puncture and computed tomography scan of the brain were both negative. Coagulation studies, including prothrombin time, partial thromboplastin time, thrombin time, fibrinogen, and D-dimers, were all normal, ruling out disseminated intravascular coagulation. A direct antiglobulin test and red cell antibody screen were negative. Red cells did not express surface $\mathrm{T}$-antigen, using anti-T antibody with peanut lectin (Arachis hypogaea).

On the basis of the severe microangiopathic hemolytic anemia in the absence of other etiologies (eg, disseminated intravascular coagulation and eclampsia), with associated renal failure, fever and seizures, she was diagnosed as having TTP. The patient was admitted to the intensive care unit and treated with daily plasmapheresis (1.5 plasma volumes each; re- placement with normal plasma), acetylsalicylic acid and dipyridamole. Diphenylhydantoin was also started because of persistent seizures. Twelve hours after presentation, her temperature rose to $39^{\circ} \mathrm{C}$ and a chest infiltrate was now seen on $\mathrm{x}$-ray. Cultures of sputum and blood taken at that time were reported on the following day as being positive for Streptococcus pneu moniae, and she was then started on intravenous penicillin.

Subsequent platelet count and clinical course are outlined in Figure 1. The patient became afebrile two days after starting penicillin. Platelet count rose steadily from day 4 and was normal by day 8 ; this was accompanied by normalization of lactate dehydrogenase, a decrease in red cell fragmentation and a gradual increase in hemoglobin. The intermittent seizures continued and were treated with diazepam, but these had resolved by day 7 ; neurological status gradually returned to normal over the ensuing 10 days. She remained oliguric for three weeks following admission and received regular hemodialysis; renal function subsequently returned to normal over the ensuing three weeks.

\section{DISCUSSION}

The patient presented with the classic pentad of thrombocytopenia, microangiopathic hemolytic anemia, neurological symptoms, renal failure and fever associated with TTP. Pneumococcal septicemia may cause fever and thrombocytopenia, but would not be expected to cause the severe microangiopathic hemolytic anemia in the absence of disseminated intravascular coagulation. This is the first reported case of TTP coincident with $S$ pneumoniae septicemia. Since the latter was detected after TTP was diagnosed, the possibility exists that the septicemia may have occurred as a complication of the underlying TTP or its treatment. However, the rapidity of onset of the septicemia (within $12 \mathrm{~h}$ of presentation) makes this less likely.

$S$ pneumoniae has previously been reported in association with the closely related hemolytic uremic syndrome in 13 patients (6-10). Hemolytic uremic syndrome is characterized by microangiopathic hemolytic anemia, thrombocytopenia and renal failure, without the prominent neurological findings typically found in TTP (4). It presents primarily in infants and children (4). Hemolytic uremic syndrome is commonly associated with infectious agents, usually Escherichia coli 0157 H7 (5), although associations with Shigella dysenteriae (12) and enteroviruses (13) have been described.

Of the 13 patients previously reported to have $S$ pneumoniae infections in association with hemolytic uremic syndrome, nine presented with pneumonia, two with meningitis and two with sepsis of undetermined origin.

All patients required dialysis and three received plasma infusion or plasma exchange. Twelve of the 
reported cases have been young children (age range five to 27 months). In these children there was a $50 \%$ mortality, whereas for hemolytic uremic syndrome in general the mortality is in the 5 to $10 \%$ range (4). Institution of appropriate antibiotics in the patients appeared to have been prompt, although in two fatal cases antibiotic use was not mentioned (10). The one adult previously reported had presented with fever, renal failure requiring hemodialysis and microangiopathy with thrombocytopenia (7). However, that patient, unlike ours, also had serological features suggestive of disseminated intravascular coagulation, including elevated fibrin degradation products and partial thromboplastin time, thus complicating the diagnosis.

$S$ pneumoniae may cause hemolytic uremic syndrome via the action of circulating neuraminidase produced by this organism $(8,10)$. Removal of $n$-acetylneuraminic acid from cell surface glycoprotein by neuraminidase exposes the normally hidden $\mathrm{T}$-antigen (Thomsen-Friedenreich) present on red blood cells, platelets and glomerular membranes. This results in deposition of naturally occurring IgM anti-T with sub-

ACKNOWLEDGEMENTS: The authors thank Olive Russell, $\mathrm{RN}$, for providing plasmapheresis support, and Judith Thomas for assistance in preparing the manuscript.

\section{REFERENCES}

1. Moschovitz E. Hyaline thrombosis of the terminal arterioles and capillaries: A hitherto undescribed disease. Proc NY Pathol Soc 1924;24:21.

2. Kwaan HC. Clinicopathologic features of thrombotic thrombocytopenic purpura. Semin Hematol 1987;24:71-81.

3. Moore JC, Murphy WG, Kelton JG. Calpain proteolysis of Von Willebrand factor enhances its binding to the platelet membrane glycoprotein IIb/IIIa: An explanation for platelet aggregation in thrombotic thrombocytopenia purpura. Br J Haematol 1990;74:457-64.

4. Kaplan BS, Proesmans W. The hemolytic uremic syndrome of childhood and its variants. Semin Hematol 1987;24:148-60.

5. Chart H, Smith HR, Scotland SM, Rowe B, Milford DV, Taylor CM. Serological identification of (Escherichia coli) 0157:H7 infection in haemolytic uraemic syndrome. Lancet 1991;337:138.

6. Alon U, Adler SP, Chan JC. Hemolytic-uremic syndrome associated with Streptococcus pneumoniae. Am J Dis sequent injury to blood cells and glomeruli (8). The presence of exposed T-antigen can be demonstrated by agglutination using peanut lectin. Of the 13 patients reported, 10 had evidence for exposed $\mathrm{T}$-antigen using this method; this was not mentioned in the one adult reported (7). In our patient we were unable to demonstrate the presence of exposed T-antigen on red blood cells. Whether this indicates another mechanism for pneumococcus-induced thrombotic microangiopathy in the present case, or that the pneumococcal septicemia was not an etiologic factor in this case, is unclear.

The treatment of choice for TTP is plasmapheresis or plasma exchange; antiplatelet agents may also be of benefit (2). Because of the small number of cases and the different varieties of therapy employed, it is difficult to determine the ideal treatment for $S$ pneumoniae-associated TTP/hemolytic uremic syndrome. The early use of aggressive plasmapheresis with antiplatelet agents, in addition to antibiotic treatment for the underlying infection, was effective therapy in this patient. This case also emphasizes the importance of searching for an underlying infectious cause in patients with TTP.

Child 1984; 138:496-9.

7. von Eyben FE, Szpirt W. Pneumonococcal sepsis with hemolytic-uremic syndrome in the adult. Nephron 1985;40:501-2.

8. Feld LG, Springate JE, Darragh R, Fildes RD. Pneumococcal pneumonia and haemolytic-uremic syndrome. Pediatr Infect Dis J 1987;6:693-4.

9. Martinot A, Hue V, Leclerc F, Chenand M. Hemolytic-uremic syndrome associated with Streptococcus pneumoniae meningitis. Eur J Pediatr 1989;148:648-9.

10. Klein PJ, Bulla M, Newman RA, et al. Thomsen-Friedenreich antigen in haemolytic-uremic syndrome. Lancet 1977;ii:1024-5.

11. Rizzoni G, Claris-Appiani A, Edefonti A, et al. Plasma infusion for hemolytic-uremic syndrome in children: Results of a multicenter controlled trial. J Pediatr 1988;112:284.

12. Koster F, Levin J, Walker L, et al. Hemolytic uremic syndrome after shigellosis. Relation to endotoxemia and circulating immune complexes. N Engl J Med 1978;298:927.

13. Karmali MA, Steele BT, Petric M, et al. Enteroviruses associated with hemolytic uremic syndrome. Pediatrics 1970;46:378. 


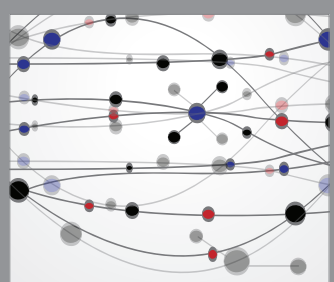

The Scientific World Journal
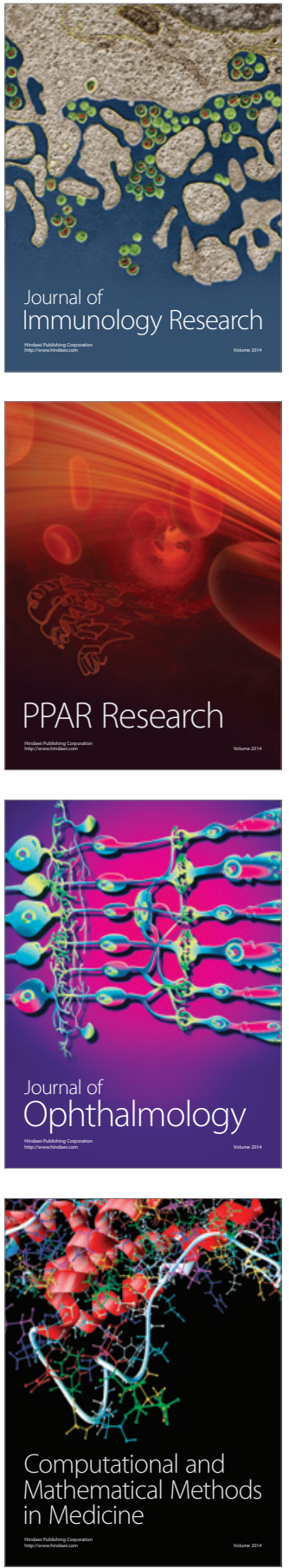

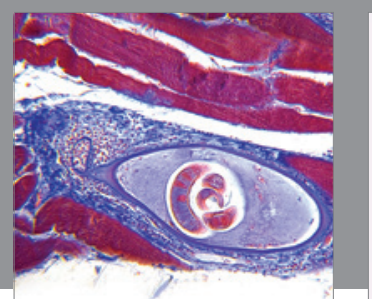

Gastroenterology Research and Practice

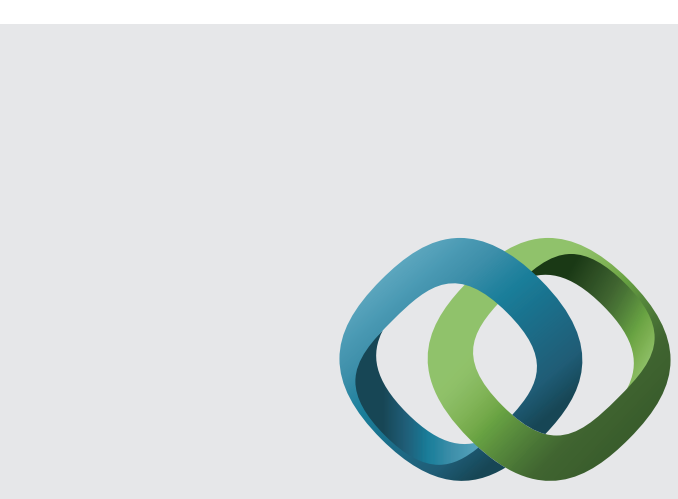

\section{Hindawi}

Submit your manuscripts at

http://www.hindawi.com
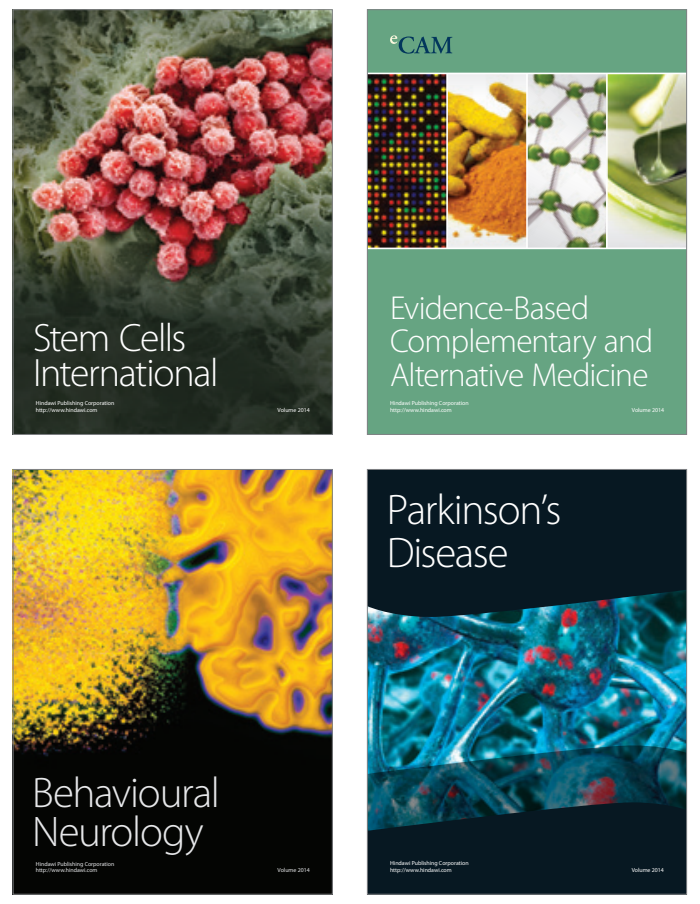
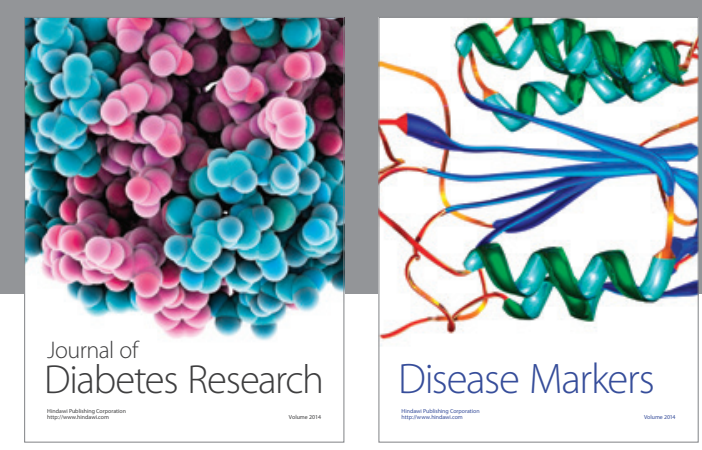

Disease Markers
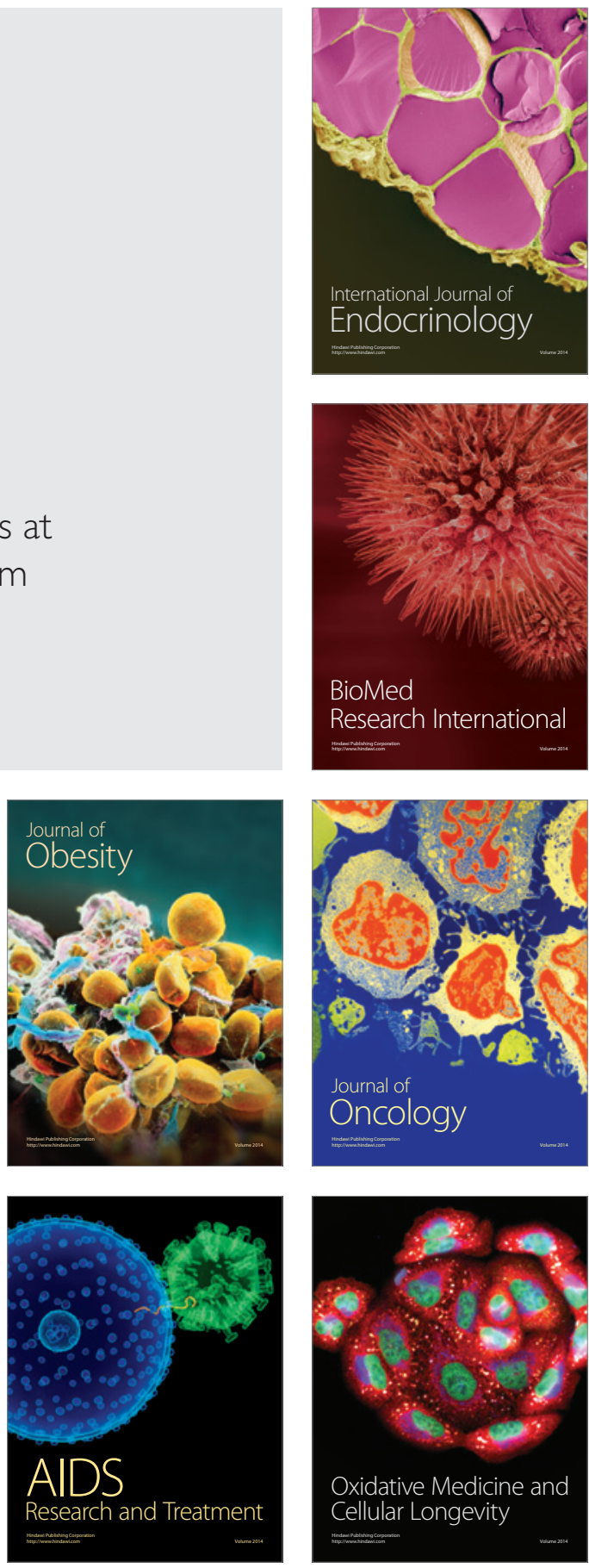